\title{
Fibrinolytic response of diabetics and non-diabetics to adrenaline
}

\author{
A. R. TANSER \\ From the Royal Sussex County Hospital, Brighton
}

SYNOPSIS The fibrinolytic response of 30 diabetic patients and 35 non-diabetics to $0.5 \mathrm{mg}$. subcutaneous adrenaline was measured, using the dilute clot lysis test. With the exception of two patients out of six who were taking phenformin, who had a depressed response, the diabetics showed a similar increase in fibrinolytic activity to the non-diabetics. The diabetics in this series did not tend to have longer spontaneous lysis times than the non-diabetics, although this type of comparison may not be valid.

Fearnley, Chakrabarti, and Avis (1963), using the dilute clot lysis test, found a low blood fibrinolytic activity more often among 100 diabetic patients than among 100 age-matched controls. Electrocardiographic evidence of myocardial ischaemia was twice as common in patients with low fibrinolytic activity as in those with more active fibrinolysis, although the figures were not statistically significant. In a smaller series, MacKay and Hume (1964), measuring the partial lysis of a dilute plasma clot, did not find that diabetics had less active fibrinolysis than nondiabetics. This agreed with the work of Denborough and Paterson (1962), who used a test similar to that of Fearnley et al. (1963).

If patients with diabetes mellitus have abnormal fibrinolysis, this might be detected by measuring spontaneous lysis times under standard conditions, although there is considerable variation in the same patient from day to day. It might be more significant to demonstrate an altered response to a standard physiological stimulus, but no suitable test has yet been described. However, non-diabetics respond predictably to a subcutaneous injection of $0.5 \mathrm{mg}$. adrenaline (Tanser and Smellie, 1964), which provides a pharmacological stimulus to fibrinolysis. In

Received for publication 14 December 1966. this paper, the response of $\mathbf{3 0}$ diabetics to adrenaline is compared with the response of 35 non-diabetics.

\section{MATERIAL AND METHODS}

LYSIS TIME The blood fibrinolytic activity was measured by a modification of the Fearnley dilute clot lysis time technique (Tanser and Smellie, 1964). A short lysis time indicated high fibrinolytic activity. Venous blood was taken before, and 20 minutes after, a subcutaneous injection of $0.5 \mathrm{mg}$. adrenaline.

THE PATIENTS The diabetic patients were volunteers attending a diabetic clinic. The first sample of blood was taken approximately two hours after breakfast. The patients had taken their usual anti-diabetic treatment.

The non-diabetics were also volunteers, and blood was taken at a similar time.

The two groups were not closely matched. Patients were included in the experiment as they volunteered. The diabetics tended to be slightly older, but even so the two groups were roughly comparable.

\section{RESULTS}

INITIAL LYSIS TIME There was no significant difference between the two groups (Fig. 1).

TABLE I

AGE IN YEARS OF DIABETICS AND NON-DIABETICS

\begin{tabular}{|c|c|c|c|c|c|c|c|c|c|}
\hline & & \multicolumn{8}{|c|}{ Age (yr.) } \\
\hline & & $10-19$ & $20-29$ & $30-39$ & $40-49$ & $50-59$ & $60-69$ & $70-79$ & Total \\
\hline Men & $\begin{array}{l}\text { Diabetic } \\
\text { Non-diabetic } \\
\text { Diabetic } \\
\text { Non-diabetic }\end{array}$ & $\begin{array}{l}1 \\
0 \\
0 \\
1\end{array}$ & $\begin{array}{l}1 \\
5 \\
1 \\
1\end{array}$ & $\begin{array}{l}1 \\
3 \\
1 \\
2\end{array}$ & $\begin{array}{l}3 \\
3 \\
4 \\
1\end{array}$ & $\begin{array}{l}6 \\
8 \\
2 \\
1\end{array}$ & $\begin{array}{l}6 \\
7 \\
1 \\
2\end{array}$ & $\begin{array}{l}2 \\
0 \\
1 \\
1\end{array}$ & $\begin{array}{r}20 \\
26 \\
10 \\
9\end{array}$ \\
\hline Women & \multicolumn{9}{|c|}{231} \\
\hline
\end{tabular}




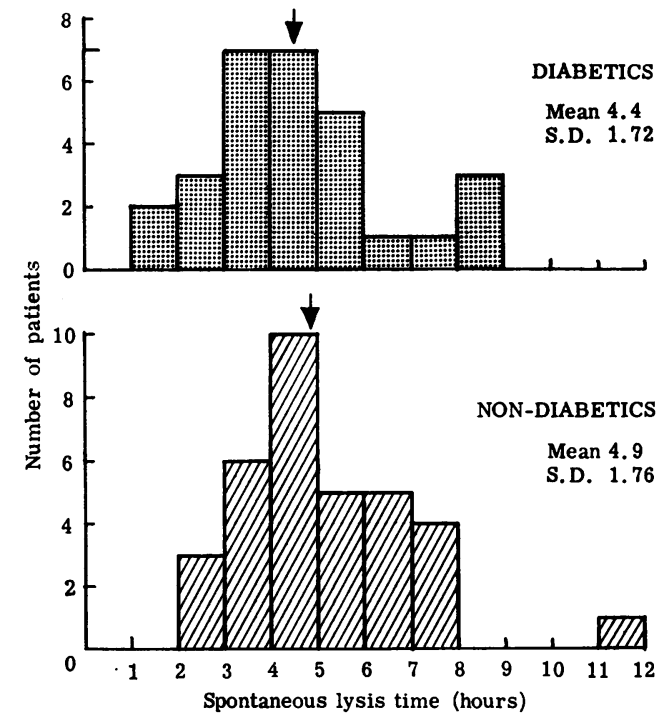

FIG. 1. Distribution of initial lysis time of diabetics and non-diabetics.

RESPONSE TO ADRENALINE The lysis time 20 minutes after the injection was shorter than the initial lysis time. The reduction in lysis time was plotted against the initial time (Figs. 2 and 3). The reduction in lysis time was proportional to the initial lysis time. The regression for non-diabetics was $\mathrm{y}=-0.06+$ $0.6338 x(\mathrm{r}=0.8541)$; and for diabetics $\mathrm{y}=-1.0$ $+0.6872 x(\mathrm{r}=0.7943)$. These results are not significantly different.

Two diabetics responded poorly to adrenaline. Both these patients were taking phenformin. Four other diabetics were taking phenformin, and these responded as expected. The two patients who responded poorly were tested in more detail on three occasions. One subsequently had a larger response to adrenaline, but the other again had a diminished and delayed response. Two normal subjects were tested with adrenaline before and after phenformin $25 \mathrm{mg}$. thrice daily for one week (Table II). There was no significant change.



FIG. 2. The reduction in lysis time 20 minutes after $0.5 \mathrm{mg}$. adrenaline in 35 non-diabetics. $y=-0.06+0.6338 x$; $r=0 \cdot 8541$.

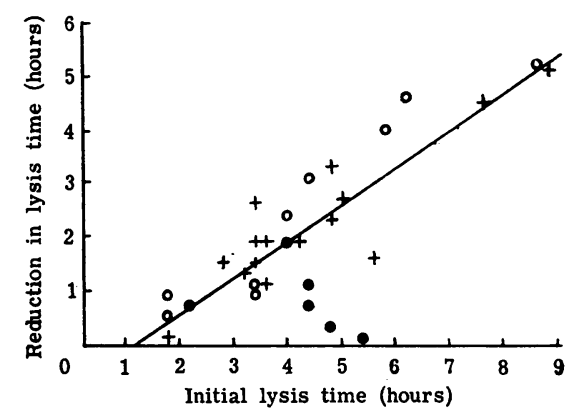

FIG. 3. The reduction in lysis time 20 minutes after $0.5 \mathrm{mg}$. adrenaline in 30 diabetics. Closed circles indicate patients taking phenformin; open circles, chlorpropamide; and crosses, insulin. $y=-1.0+0.6872 x ; r=0.7943$.

\section{DISCUSSION}

These results suggest that diabetic patients respond to injected adrenaline with the same increase in fibrinolysis as non-diabetics.

It is not possible to conduct a strictly controlled comparison between diabetics and non-diabetics because most diabetics require treatment with insulin, sulphonylureas, or phenformin, all of which

\section{TABLE II}

THE RESPONSE TO ADRENALINE BEFORE AND AFTER PHENFORMIN $25 \mathrm{mg}$. THRICE DAILY FOR ONE WEEK

\begin{tabular}{|c|c|c|c|c|}
\hline \multirow[b]{2}{*}{ Subject } & \multicolumn{2}{|c|}{ Before Phenformin } & \multicolumn{2}{|c|}{ After Phenformin } \\
\hline & $\begin{array}{l}\text { Initial Lysis } \\
\text { Time (hr.) }\end{array}$ & $\begin{array}{l}\text { Reduction } \\
(\boldsymbol{h r} .)\end{array}$ & $\begin{array}{l}\text { Initial Lysis } \\
\text { Time (hr.) }\end{array}$ & $\begin{array}{l}\text { Reduction } \\
\text { (hr.) }\end{array}$ \\
\hline $\begin{array}{l}\text { S.W. } \\
\text { A.T. }\end{array}$ & $\begin{array}{l}4,0 \\
4,0\end{array}$ & $\begin{array}{l}2,3 \\
2,3\end{array}$ & $\begin{array}{l}6.0 \\
5.0\end{array}$ & $\begin{array}{l}4,5 \\
1,5\end{array}$ \\
\hline
\end{tabular}


influence fibrinolysis (Fearnley et al., 1959; Fearnley and Chakrabarti, 1964). This may affect measurements of spontaneous fibrinolysis, and certainly makes the interpretation of such studies more difficult. Within these limitations, this study did not suggest that diabetics have longer lysis times than controls, thus supporting the work of Denborough and Paterson (1962) and MacKay and Hume (1964).

The poor response to adrenaline in two out of six patients taking phenformin was an incidental finding, but the data are insufficient to speculate on possible causes.

These results do not support the suggestion that diabetics have abnormal fibrinolysis which might make them more liable to occlusive vascular disease.
This study was supported by a grant from the SouthEastern Metropolitan Regional Hospital Board.

I am grateful to Dr. C. Barrington Prowse and Dr. J. K. Wagstaff who allowed me access to their patients. Dr. Clifford Riley and Mr. John Cook gave me generous laboratory facilities and help. Mrs. Sandra Walton measured the lysis times.

I am grateful to Professor W. M. Davidson and Dr. P. T. Flute for valuable criticism.

\section{REFERENCES}

Denborough, M. A., and Paterson, B. (1962). Clin. Sci., 23, 485. Fearnley, G. R., and Chakrabarti, R. (1964). Acta cardiol. (Brux.), 19,1 .

- and Avis, P. R. D. (1963). Brit. med. J., 1, 921.

, Vincent, C. T., and Chakrabarti, R. (1959). Lancet, 2, 1067.

MacKay, N., and Hume, R. (1964). Scot. med. J., 9, 359.

Tanser, A. R., and Smellie, H. (1964). Clin. Sci., 26, 375. 